\title{
Neuropathic urinary retention in the absence of neurological signs
}

\author{
PA Sylvester, J McLoughlin, GN Sibley, PJ Dorman, J Kabala, IEC Ormerod
}

\begin{abstract}
Summary
We present two cases of painless urinary retention secondary to central intervertebral disc prolapse. In neither case were there signs or symptoms suggesting an underlying neurological insult. Both patients voided spontaneously following neurosurgical intervention. The classical features of acute cauda equina compression may be absent in patients with central lumbar disc protrusion. Painless urinary retention may be the only physical sign.
\end{abstract}

Keywords: intervertebral disc, urinary retention

Development of a neuropathic bladder is a well-recognised complication of intervertebral lumbar disc prolapse. ${ }^{1,2}$ In the cauda equina syndrome painless urinary retention may accompany other urinary and neurological symptoms when resulting from a posterolateral protrusion with medial encroachment. ${ }^{3}$ However, central disc prolapses may not produce any somatic effects, thereby evading clinical detection. In 1967, Emmett and Love ${ }^{4}$ reported two cases of urinary retention in patients with cauda equina syndrome but no neurological deficit. This group of patients has often been neglected. We describe two cases in whom central lumbar disc protrusion 'silently' led to painless urinary retention. In neither patient was there any associated urinary or neurological signs, retention being the only feature.

Bristol Royal

Infirmary,

Marlborough Street,

Bristol BS8, UK

Department of

Urology

PA Sylvester

$\mathrm{J}$ McLoughlin

GN Sibley

Department of

Neurology

PJ Dorman

IEC Ormerod

Department of

Radiology

J Kabala

Correspondence to

Mr J McLoughlin,

Consultant Urologist, West

Suffolk Hospital, Bury St

Edmunds, Suffolk IP33 2QZ, UK

Accepted 1 June 1995

\section{Patients and methods}

Case 1

A 17-year-old woman presented with a fourday history of painless retention of urine. She had been able to expel small quantities of urine by a combination of applying pressure to her anterior abdominal wall and taking regular diazepam which had been prescribed by her practitioner. No precipitating factors nor history of trauma was identified in the history at that time. A full clinical assessment failed to elicit any neurological deficit. Magnetic resonance imaging (MRI) performed on admission showed central prolapse of a degenerate L4/5 disc coupled with a narrowed spinal canal (figure 1). In addition, minor degenerative changes were found at the L3/4 and L5/S1 levels. It was noted that the patient found it difficult to lie flat in the MRI scanner and she then admitted to experiencing some minor lower lumbar discomfort over the preceding several weeks. Following urgent microdiscectomy and decompression of the L4/5 disc she returned to spontaneous voiding in the early postoperative period with minimal residual urinary volumes. At three month review she had returned to her normal voiding pattern.

\section{Case 2}

A 31-year-old woman presented to casualty with painless retention of urine. She had complained some months before of symptoms of frequency, urgency and haematuria for which no cause had been found. On neither occasion was there a history of a recent fall, trauma or precipitating event. In the absence of any clinically evident neurological deficit this was initially managed by intermittent selfcatheterisation. She encountered urethral discomfort and was admitted for suprapubic catheter insertion. Whilst an in-patient, MRI of her lumbo-sacral spine showed a moderate lumbar central disc protrusion at the level of L4/5 interspace coupled with a long-standing mild degree of spinal stenosis (figure 2). Minor degenerative changes were also noted at L3/4 level. This patient also then admitted to minor lower lumbar discomfort on occasions for some time prior to presentation. She underwent neurosurgical decompression following which she resumed spontaneous voiding, leaving no

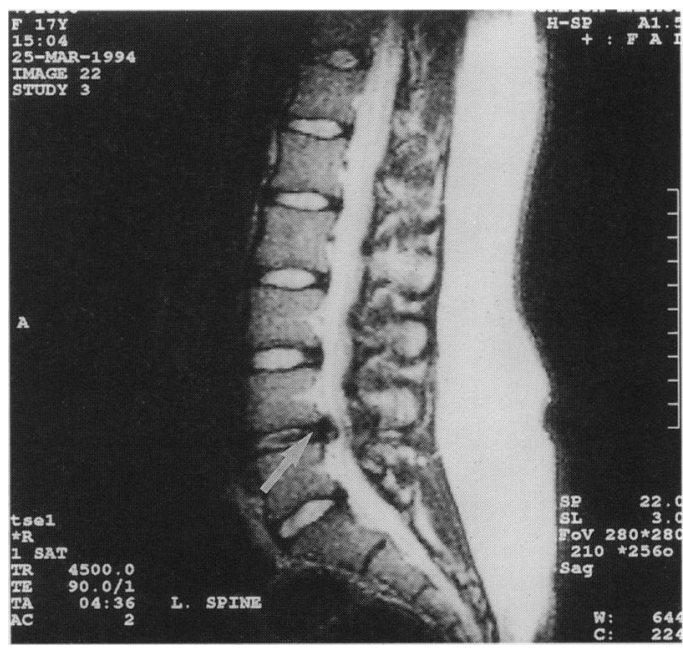

Figure 1 Sagittal T2-weighted MRI demonstrating a degenerate $\mathrm{L} 4 / 5$ disc, with dehydration, and large central disc protrusion 


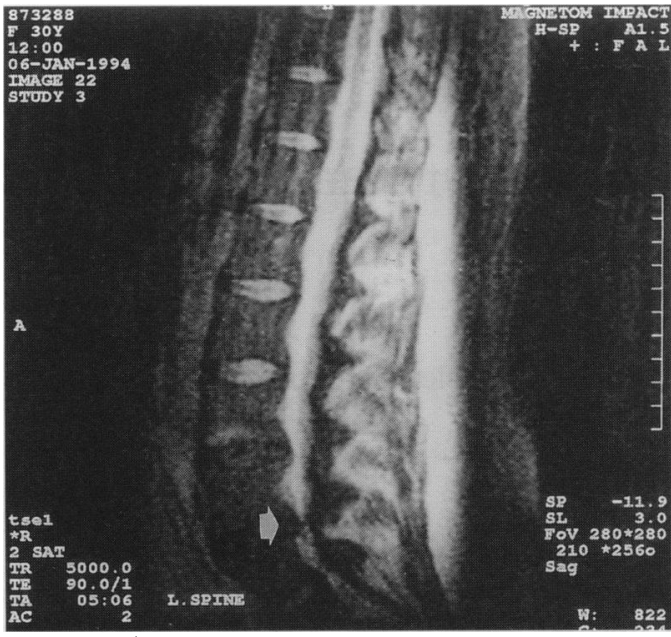

Figure 2 Sagittal T2-weighted MRI demonstrating a degenerate L4/5 disc with central disc prolapse accompanied by a narrowed spinal canal

residual urine by the second postoperative day When reviewed at four months she was free of urinary symptoms.

\section{Discussion}

The differential diagnosis of a female patient presenting with urinary retention includes neurological insult resulting from multiple sclerosis or disc protrusion, a retroverted gravid or fibroid uterus, dysfunctional voiding and anticholinergic side effects of systemic medication. Disc protrusion may give rise to a cauda equina syndrome, the classical features having been described elsewhere, ${ }^{3}$ and include constipation, voiding disturbances (most frequently retention) and, in the male patient, impotence. Pain and immobility may feature when root compression is secondary to a posterolateral disc protrusion. Peri-anal sensory loss and laxity of the anal sphincter are important physical signs and may be missed in a less than thorough physical examination. In neither of our cases were such a deficit detected, despite examination by both urologist and neurologist, even in retrospect. Two similar cases were described in $1967^{4}$ whilst in 1973 Jones et al identified a group of five patients presenting for urodynamic investigation with a range of voiding abnormalities who had central disc protrusions, a proportion of whom had neither symptoms nor signs traditionally attributed to lumbar disc disease. ${ }^{5}$

The retrospectively obtained history of back pain in both patients is important as, while

1 Malloch JD. Acute retention due to intervertebral disc prolapse. $\mathrm{Br} \mathcal{F}$ Urol 1965; 37: 578.

Scott PJ. Bladder paralysis in cauda equina lesions from disc prolapse. F Bone foint Surg 1965; 47: 224-35.

3 O'Flynn KJ, Murphy R, Thomas DG. Neurogenic bladde dysfunction in lumbar intervertebral disc prolapse. $B r f$ Urol 1992; 69: 38-40.

4 Emmett JL, Love JG. 'Asymptomatic' protruded lumbar disc as a cause of urinary retention: preliminary report. Mayo Clin Proc 1967; 42: 249.

5 Jones DL, Moor T. The types of neuropathic bladder dysfunction associated with prolapsed intervertebral discs. Br ₹ Urol 1973; 45: 39-43.

6 Ross JC, Jameson RM. Vesical dysfunction due to prolapsed 6 Ross JC, Jameson RM. Vesical
disc. $B M \mp$ 1971; 3: 752-4.

\section{Learning points}

- painless urinary retention may have an underlying neurological cause

- central disc protrusion may have minimal or no associated somatic symptoms

neither presented with or admitted to discomfort at the time, such symptoms may determine whether a patient with an initially negative investigation requires neuro-imaging.

Jones $e t a l^{5}$ suggested that the neuropathic insult could produce a range of symptoms depending on the degree of root compression. This could range from detrusor hyperreflexia, as the nerve roots are initially irritated by disc pressure, to areflexia as the degree of compression increases. In contrast, $\operatorname{Ross}^{6}$ suggested that the first manifestation of such bladder dysfunction was actually impaired sensation. Both these clinical pictures could describe our patients who were found to have significant compression at presentation.

In the past the investigation of such patients would have required myelography and/or computed tomography. However with the advent of MRI the detection of intervertebral disc prolapse has become easier and should, where available, be considered early in the management of patients suspected of developing retention secondary to an acute neurological insult. In addition, plaques of demyelination resulting from multiple sclerosis can also be visualised.

These two cases highlight a number of points of clinical importance. In neither patient were there any features at the time of initial presentation indicating either a predisposition towards disc prolapse, or the existence of root compression, except painless urinary retention. Both patients were young, fully mobile and otherwise asymptomatic. Painless retention should be considered as a clinical sign on its own merits, even in the absence of any other neurology or indeed symptoms. Secondly, both patients were able to void post-decompression despite a time lapse between onset of original symptoms and decompression in both cases. There is no clear correlation between delay before surgery and outcome in cauda equina syndrome due to disc protrusion..$^{7-10}$ Hence, whilst diagnostic delay is to be avoided it should not dissuade the clinician from considering neurosurgical referral as it does not necessarily preclude a favourable outcome. It remains true, however, that only by clinicians maintaining a high index of suspicion will such cases be identified.

7 Gleave JR, MacFarlane R. Prognosis for recovery of bladder function following central disc prolapse. $\mathrm{Br} \mathcal{F}$ Neurosurg 1990; 4: 205-9.

8 Shapiro, S. Cauda equina syndrome secondary to lumbar disc herniation. Neurosurgery 1993; 32: 743-6.

9 Kostiuk JP, Harrington I, Alexander D. Cauda equina syndrome and lumbar disc herniation. $\mathcal{f}$ Bone foint Surg 1986; 68A: 386-91.

10 O'Laoire SA, Crockard HA, Thomas DG. Prognosis for sphincter recovery after operation for cauda equina compression owing to lumbar disc prolapse. $B M \mathcal{F} 1981 ; 282$ 1851-4. 